with the injured joint, or joints, immersed in a suitable bath with a positive electrode unit so that a current of 2-3 milliamperes could be passed. The results were most satisfactory, the treated group returning considerably earlier to full duty than the remainder. Unfortunately this suggestive trial experiment roused no interest or furthe test or follow-up. All this not 50 years ago but nearer half that.

With all the incredible advances in the use of electricity on other fronts in the last 25 years why then in medicine alone has there been not only no advance but retrogression? What is needed is a determined and properly sponsored attack on these claims, routing out and condemning the specious while proving to the satisfaction of the profession the value and field of use of those that survive.-I am, etc.

Chipping Camden,

C. B. Heald

\section{Lumbar Disc Problems}

SIR,-I feel that Mr. A. H. G. Murley (26 August, p. 529) has been unfairly criticized for drawing attention to a common misconception that all leg pain accompanying lumbar disc lesions is due to nerve root irritation. I do not think that any of us will deny that disc lesions are commonplace, but I cannot accept Dr. R. T. D. FitzGerald's statement (14 October, p. 116) that the posterior joints "are rarely capable of being the cause of the pain." James Cyriax certainly has pointed out that posterior joint arthrosis in isolation is rare but there can be no question that as a sequal to disc degeneration it is common enough, and I would strongly support Mr. Murley's view that quite a lot of leg pain in this disease is segmental (scleratogenous) pain referred from the posterior joints and probably from other mesodermal structures also. It is characteristically a deep-seated ache in the muscles of the leg which does not spread below the knee, unlike root pain, and which is not associated with any sensory or motor disturbance.

May I also take issue with the implication in Dr. FitzGerald's letter that backache, whether it is of long standing or not, is generally cured by manipulation or traction. Root pain may be but backache seldom is. While commending his enthusiasm for manipulation of the lumbar spine, may I add a word of caution? Like manipulation anywhere it has its complications, but whereas a completely torn meniscus (if I can use his analogy) can be excised at leisure an acute central disc protusion requires prompt removal.-I am, etc.,

R. K. JACKSON

Southampton

\section{Nurses for Nursing}

SIR,-One of the most disturbing consequences of the implementation of the Salmon report has been the deplorable practice of referring to senior members of the nursing profession as numbers. People designated by ciphers behave as ciphers. Why then has this happened? The answer lies in the titles "chief nursing officer," "principal nursing officer," and "senior nursing officer," chosen by the committee. In the first place there is no need to refer to senior nurses as "officers," a title with military connotations which is quite alien to the nursing pro- fession. Secondly, the words "chief" and "principal" have the same meaning, and so, very nearly, does "senior." Thus there are three almost identical titles which are not distinguishable from one another either to the holders' colleagues or to people outside the hospital environment. The desire to do away with the designation "matron" has much to do with this.

The new post of chief nursing officer, or Salmon No. 10, with her part to play in decision and policy making at group level, is welcome, but why should she not be known as "group matron," a name that at once indicates her role and status? Moreover, the existence of a principal nursing officer (Salmon No. 9) between the group matron and a hospital matron diminishes the status and self-reliance of the latter. In a hospital in which I work there is a triumvirate of No. $8 \mathrm{~s}$, one for the daytime, one for the night-time, and one for the operating theatres. The result of this remarkable arrangement was predictable: it is difficult to find anyone really responsible for anything and the No. 9 in charge has two or three other hospitals to look after as well A hospital is a clearly defined unit of varying size and complexity. The responsibility for the recruitment, the deployment, the wellbeing, and the discipline of the nurses in it should be vested in a single individual, the matron, whose status and salary should depend upon the size of the hospital. In some cases this could be a No. 9 post and in others a No. 8 or No. 7, and the holder of this post should, in most cases, be directly responsible to the group matron.

The ward sister is the key person in the nursing care of patients. While in som circumstances the nursing managerial role of a nursing officer (Salmon No. 7) can indeed be integrated with the work of ward sister, in other situations this may be quite inappropriate. Ward sisters in a specialized unit often have more knowledge and experience of their specialties than the nursing officer under whom they work. Such ward sisters may have no prospects of promotion unless they leave their specialty and take up an administrative role. It should be possible for experienced ward sisters to be promoted to the status and salary of a nursing officer while still remaining in direct clinical work.

I hope and believe that it is not too late for the results of implementation of the Salmon report to be re-examined, and that nurses at all levels in the service should be closely involved in such a scrutiny.-I am, etc.

Walsgrave Hospital,

IAN R. GRAY Coventr

SIR,-First Salmon and now Briggs. ${ }^{1}$ Both reports aim at producing an academic professional rather than a practical nurse. Why is it that we lay such store by training courses and so little by maturity and experience? Why is it assumed that a nurse tutor must have a diploma in order to be able to teach? Even in universities there are professors with no more than a first degree (and my experience of them has been that in both teaching and research they are as good as any).

Many of the things which matter most in medicine and nursing simply cannot be taught - things such as judgement, kindness, wisdom, and even that rare commodity common sense. To compound its error the Briggs Committee suggests that nurses should eventually start their training at the age of 17. Even if the training were purely academic there are many (myself among them) who think that higher education starts too soon, and that the usual age of entry to universities, etc., should be raised from 18 to 19 to allow the students to mature somewhat. I can assure you that the extra year pays the student a handsome dividend. But nursing is not an academic career: it requires a certain maturity and experience of life in order to learn and practise it successfully. Seventeen is much too young to start.

I sometimes think that soon our society will consist of nothing but students and teachers and no one will be left to do the work. We already have university departments of nursing for those who want an academic approach to the subject. For heaven's sake let us keep to a sensible, practical approach to nursing for the majority who do not.-I am, etc.,

Medical Centre

T. C. DANN

University of Warwick

1 Committee on Nursing (chairman, Professor Asa
Briggs), Report, Cmnd. 5115. London,
H.M.S.O., 1972.

\section{Self-poisoning with Drugs}

SIR,-Dr. A. J. Smith, in his report on selfpoisoning in Sheffield (21 October, p. 157) draws some conclusions which I feel are unjustified.

In recent years Sheffield medical units have as a rule admitted patients presenting with self-poisoning willy-nilly-for psychiatric and medicolegal reasons rather than purely medical ones. Was this so 10 years before, when the Parkin and Stengel study ${ }^{1}$ was done? Furthermore, according to the figures given there seems to have been a maked decrease, both absolute and relative, in the completion rate of suicidal attempts over the same period. Surely it is preferable that the disturbed should rake a small handful of tranquillizers than that they should launch themselves from the nearest rooftop (coal-gas being no longer available).-I am, etc.

Leeds, Yorks.

C. L. Tolhurst-Cleaver

Parkin, D., and Stengal, E., British Medical
fournal, 1965, 2, 133 .

\section{Self-poisoning with Paracetamol}

SIR,-Self-poisoning in Britain has now reached epidemic proportions. ${ }^{1}$ However, not only has the incidence been mounting (Dr. A. J. Smith, 21 October, p. 157) but also the agents used have been changing.

Until recently self-poisoning with paracetamol was rare but overdoses of this drug, which is freely available without prescription in large quantities, now account for $10 \%$ of admissions for self-poisoning to the Radcliffe Infirmary. This letter is prompted by the death while under our care of a patient who had taken $40 \mathrm{~g}$ of paracetamol. The clinical details of this case do not differ from the recorded effects of paracetamol poisoning, ${ }^{2}$ but the nature of the toxic effects and the increasing use of paracetamol in sclfpoisoning suggested to us that some control should be placed upon its sale.

The patient, a 30-year-old woman physically in excellent health became de- 
pressed and took from the bathroom cupboard $80500-\mathrm{mg}$ paracetamol tablets which had been bought by a relative for toothache. Immediately after taking the tablets she greatly regretted her action and had no wish to die. For 24 hours her clinical condition was excellent and she repeatedly asked to go home. On the second day in hospital acute hepatic failure developed together with a severe oliguria with the characteristics of acute tubular necrosis. She died shortly afterwards and gross hepatic and renal damage were found at necropsy.

This tragic case emphasizes some of the dangers of self-poisoning with paracetamol. There is no recognized effective treatment for the toxic effects of paracetamol once the drug is absorbed..$^{2-4}$ The very minimal initial symptoms ensure that medical advice is not sought at a stage when gastric lavage might prevent further absorption. There is a general misconception that paracetamol is a safe drug and for this reason may be chosen in preference to aspirin in attempted suicide.

It would therefore seem reasonable to suggest that paracetamol should become a prescription drug instead of being freely available in large quantities to those who wish only to make a suicidal gesture.-We are, etc.,

Peter Barnes Radcliffe Infirmary,

J. S. Prichard Oxford

1 Matthew, H., British Medical fournal, 1971, 1, 2 Proudfoot, A. T., and Wright, N., British Medi2 Proudfoot, A. T., and Wrigh

3 Farid, N. R., Glynn, J. P., and Kerr, D. N. S., 4 Matthew, H., Lancet, 1972, 2, 607.

\section{Poisoning Treatment Centres}

SIR,-The excellent research of Dr. Peter Kennedy (4 November, p. 255) reveals that those patients who have taken an overdose at a time of emotional crisis and are then admitted to this Regional Poisoning Treatment Centre are only one-third as likely to repeat the act as those not so admitted. I am sure social work intervention helps, and perhaps even the physician and psychiatrist, but I wonder too if there is not some more potent feature.

The consummatory nature of the drama need not be seen only in the pill-swallowing, the ambulance ride, the white coats, and the long corridors, but also in the gastric lavage. The Jacques tube is thrust-red, lubricated, and of quite daunting diameterdeep into the primal orifice. The climax comes as the flood-gates open, the panting exaltation seems never-ending till, at long last and before the small gathering, the dripping instrument is withdrawn. A new peace now dawns, life and hope are reborn. Those who survive never forget.

It is surely a procedure of appeal to theoreticians, whether materialistic behaviour therapists or fervid Freudians like myself. So, as I post a copy of this letter to Dr. Kennedy in the next office, I ask if he can tell us if there was any difference in overdose repeat rate among those who did or did not receive a stomach washout. And, for good measure, among those who were or were not transferred for further psychiatric care.-I am, etc.,

\section{Accident Flying Squad}

SIR,-Those of us who have been privileged and able to practise primary care of the injured at the locus of accident are in no doubt that a proportion of lives have been saved by the measure. We improve the victim's condition before a safer ambulance ride, and the categories of "dead on arrival" are diminished.

Dr. R. Snook's most important pronouncement (28 October, p. 238) is for me his advocacy of the upgrading of ambulance men. We have skilled anaesthetic technicians expert laboratory workers, plaster of paris adepts. Why then not similarly highly trained men in the vital ambulance service? Towards this end my suggestion is for secondment for a minimum period of three month to the accident department of a provincial hospital. I would not approve attachment to the serene academic atmosphere of a teaching hospital. The daily rough and tumble of the work, plumb within the industrial belt, would afford the necessary tuition in intubation under the most adverse positional conditions, in the use of infusion fluids, and the recognition of the varying degrees of surgical shock.

My proviso is that out in the field the advanced ambulance technician would carry out these manoeuvres and administer prescribed drugs only under the permissive direction of the accident officer at the central base by radiotelephony. In France colleagues have experimented with relayed television close-ups of the injured from the wagon. This may be for the future, but we already have the method in Edinburgh Royal Infirmary; from the casualty department views of head cases can be sent to the distantlybased neurosurgeon.

I have one niggling objection to the title which heads this letter. In the off-shore islands (Hebrides, Orkney, and Shetland), where there is an inter-island aeroplane service for freight and passengers, the people immediately think the designation connotes a flying-doctor service for them. This can lead to embarrassment at times. Emergency accident care, or such like. is more universally appropriate.-I am, etc.

Grimsby, Lincs

Daniel Lamont

\section{Conscientious Objection to Abortion}

SIR - The points raised by Mr. R. L. Walley (28 October, p. 234) are of tremendous relevance and importance. We attempt to stifle the conscientious objections of members of our profession at our peril. I was horrified as a general practitioner at a recent meeting to witness the naked aggression shown by some of my colleagues towards a gynaecologist who instead of rubber stamping their referral requests for abortion sought only to retain his elementary right to make his own decision in each case.

It is surely never part of professional duty to satisfy as they stand our patients' "on demand" requirements in any branch of medicine. The effective therapy we try to provide is not necessarily synonymous with that sought, and when we allow the two to diverge is it not because we consider that by so doing the patients needs are being more fully and conscientiously met? Why should gynaecology be the only province where the "on-demand" principle must steam-roller any conscientious objection and where capitulation must be the response to each and every request?

One can only say that this country will be the poorer if men of Mr. Walley's calibre are forced to seek other avenues of service than those for which they are specifically equipped.-I am, etc.,

Cardiff,
Glam

MARGARET WILKINSON

\section{Influenza and Infant Mortality}

SIR,--In their interesting paper Dr. G. Wynne Griffith and others (2 September, p 553) write: "The possibility that influenza infection of a pregnant woman might adversely affect the fetus has been considered by several investigators, but almost without exception they have sought teratogenic effects."

I would like to call your attention to an exception. A Hungarian study ${ }^{1}$ showed that the birthweights of babies of women who had had influenza during the last months of pregnancy were lower (under 2,500 g) than those of unaffected women in about $5 \%$ of cases. A decrease in livebirths nine months after influenza epidemics was also demonstrated. But no correlation was found between the monthly stillbirth rate or the rate of spontaneous abortions and the peak months of influenza epidemics from 1950 to 1965. The details of this study were published only in Hungarian. ${ }^{2}-\mathrm{I}$ am, etc.,

A. Czeizel

Laboratory of Human Genetics,

National Institute of Public Health,

Czeizel, A., Tusnady, G., Domáry, Z., and 2 Czeizel, A., Lemografia, 1968, 2,231

\section{Acute Bed Requirements}

SIR,-Mr. Mark Wheeler, in his article "How Many Acute Beds do we Really Need?" (28 October, p. 220), has shown that an acute bed/patient ratio of 1:92 would appear adequate in the Bury St. Edmonds area, and that a similar acute bed ratio could be achieved on a national scale even without waiting for new buildings and expanded community services. A further comment from the point of view of the health and social services on the results in Bury St. Edmonds would be most interesting. Are these services under any special strain? Will they have to be specially increased to cope with the acute bed situation? Are there any special arrangements for district nurses to look after those discharged early from hospital? - I am, etc.,

A. Ross

Health Department,

SIR,-I should like to comment further on your leading article (30 September, p. 782) on Raynaud's disease. Firstly, vou state that in the "C.R.S.T. syndrome (calcinosis. Raynard's disease, sclerodactyly, and telangiectasia) the prognosis is good even if the patient has oesophageal aperistalsis." But in my experience this has not always been the case. Then there is another aspect you do not mention. 